\title{
Design and Analysis of Axial Flux Permanent Magnet Synchronous Machine
}

\author{
Won-Young Jo*, In-Jae Lee*, Yun-Hyun Cho ${ }^{\dagger}$, Dae-Hyun Koo** and Yon-Do Chun**
}

\begin{abstract}
In this article, a special kind of axial flux permanent magnet machine has proved to be suitable for high torque and low speed applications. An innovative design of the machine has been proposed in order to make the machine suitable for traction applications by means of field-weakening. The aim of this paper is to analyze, in general terms, the basic equations that describe the operating conditions of such machines. Optimal sizes for design can be obtained by calculating the power density and the air-gap flux density, etc.
\end{abstract}

Keywords: Axial flux permanent magnet synchronous machine (AFPMSM), Design strategy, Field weakening, Optimal size, Power density

\section{Introduction}

Recently, many factors point to the necessity of introducing a new propulsion concept for transportation vehicles. The exhausts emitted by the internal combustion engine of passenger vehicles, trucks and busses alike such as $\mathrm{CO}, \mathrm{SO}_{2}$, and $\mathrm{NO}_{\mathrm{x}}$ have proved to be severe air pollutants effecting the quality of life in many aspects. Hybrid cars represent a solution to the problem of pollution. A very important issue in any hybrid vehicle is the limited space available inside the vehicle. With this in mind, axial flux permanent magnet (AFPM) machines represent an optimal solution. In fact, the higher torque density of these machines, compared to the conventional radial flux machines, results in considerable space reduction. The innovative AFPM machine design, presented in this paper, is obtained by adding stator teeth to the conventional airgap wound stator [1-2].

In this paper, the machine enables us to reach high speeds in field-weakening operation. The main equations used for the design of the machine will be presented in the following part. As well, the general sizing equations can be applied to axial flux permanent magnet synchronous machine (AFPMSM) topologies and optimum machine design with high power/torque density, air-gap magnetic

$\dagger \quad$ Corresponding Author: Dept. of Electrical Engineering, Dong-A University, Korea. (yhcho@dau.ac.kr)

* . Department of Electrical Engineering, Dong-A University, Korea. (j06554@donga.ac.kr)

** Mechatronics Research Group, Industry Applications Research Laboratory, Korea Electrotechnology Research Institute, Korea.

Received 9 May, 2005 ; Accepted 10 October, 2006 flux density and high performance can be achieved [1-5].

\section{Design Strategy}

The driving characteristics of a typical drive application requires that for the steady state of the time, the machine has to operate with the output power of $15[\mathrm{~kW}]$, the output torque of $100[\mathrm{Nm}]$, and the speed of up to $1800[\mathrm{rpm}]$, respectively. The peak torque is $200[\mathrm{Nm}]$ at $1350[\mathrm{rpm}]$. The maximum output speed is $2600[\mathrm{rpm}]$, which is set by the maximum speed of the industrial diesel engine.

In keeping with general motor design practice, a winding coil current density of $4\left[\mathrm{~A} / \mathrm{mm}^{2}\right]$ (root-mean-square value) has been chosen as the continuous safe current loading. The average practical safe operating value will depend on the duty cycle of the machine [3-4].

\section{General Description}

\subsection{Stator and Rotor Configuration}

The AFPMSM was designed with a single rotor, a double-sided airgap, and stators. The isotropic rotor is placed between teeth of the double-sided stators as shown in Fig. 1. The stator back yokes are attached to the lateral case covers of the motor. The lateral case covers are made with rolled steel material. The stator teeth are individually fixed to the stator disk. The fan-shaped magnets of the rotor are mounted in holes of the rotor disk without the back yokes. Fig. 2 shows the structure of the AFPMSM [6-8]. 


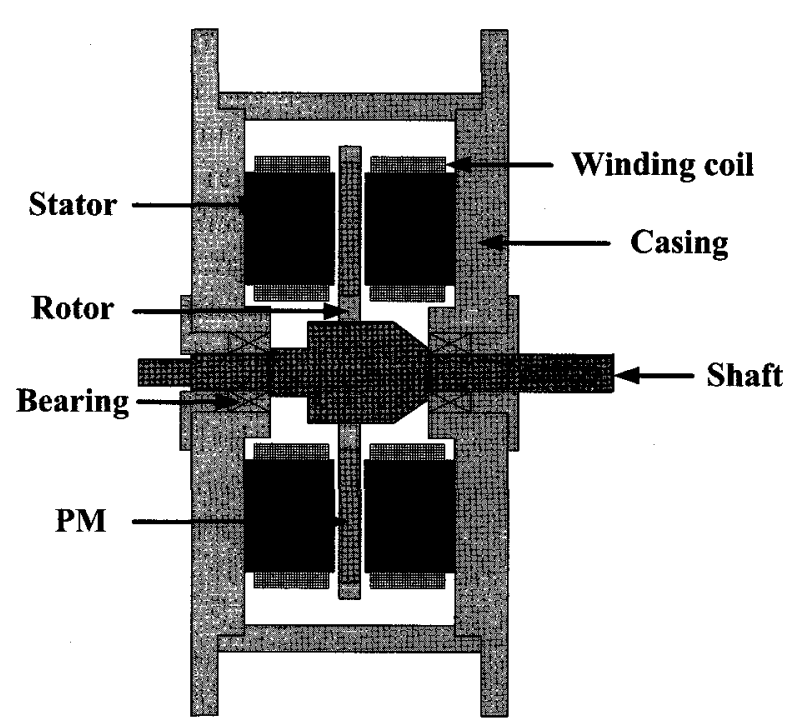

Fig. 1. Cross section view of the AFPMSM

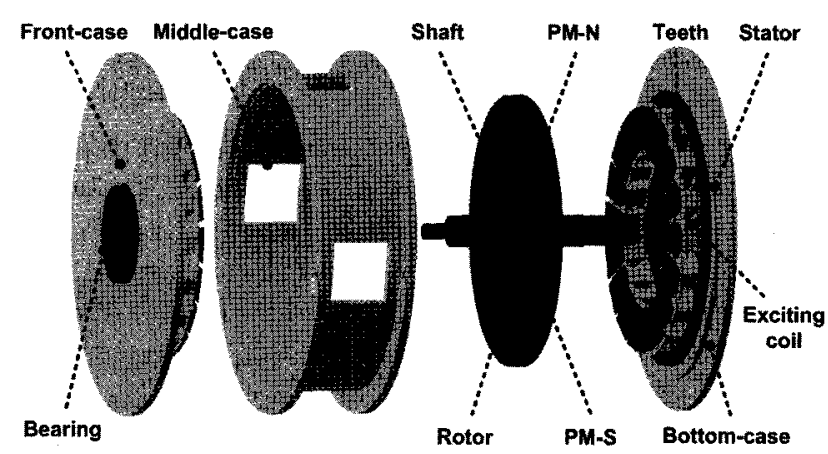

Fig. 2. The structure of the AFPMSM

\subsection{Coil Windings}

The stator windings must fulfill the following requirements $[3-5]$ :

- Must use the concentric winding method to allow easier manufacture.

- Must obtain a sinusoidal distribution of the magneticmotive force in order to avoid torque pulsations.

- The winding factors (the distribution factor and the pitch factor) must have high values so that the output power does not decrease.

The construction of winding as shown in Fig. 2 satisfied most of the above requirements. The MMF produced by the winding coils can be expressed by the Fourier series:

$$
\operatorname{MMF}(x)=\sum_{n=1,3, \cdots}^{\infty} b_{n} \sin (x)
$$

For a maximum value of $M M F(x)$ is 1 , the Fourier coefficients are shown in Table 1.
Table 1. Fourier coefficients of the MMF

\begin{tabular}{|c|c||c|c|}
\hline $\mathrm{N}$ & $\mathrm{b}_{\mathrm{n}}$ & $\mathrm{n}$ & $\mathrm{b}_{\mathrm{n}}$ \\
\hline 1 & 1.065 & 13 & -0.082 \\
\hline 3 & 0 & 15 & 0 \\
\hline 5 & -0.057 & 17 & 0.017 \\
\hline 7 & 0.041 & 19 & -0.015 \\
\hline 9 & 0 & 21 & 0 \\
\hline 11 & -0.097 & 23 & 0.046 \\
\hline
\end{tabular}

The winding factors for the fundamental are defined by the expressions:

$$
k_{d}=\frac{\sin \left(q \alpha_{r} / z\right)}{q \sin \left(\alpha_{r} / z\right)} \text { and } k_{p}=\sin \left(\frac{\beta \pi}{2}\right)
$$

where, $k_{d}$ is the distribution factor, $k_{p}$ is the pitch factor, $q$ is number of slots per phase and per pole, $a_{r}$ is electrical degrees corresponding to one slot, $\beta=y / \tau, y$ is the coil span in number of slots, and $\tau$ is the polar pitch in number of slots. Finally the winding factor $k_{w}$ is given by:

$$
k_{w}=k_{d} k_{p}
$$

\section{Electromagnetic Design}

\subsection{Torque Calculation}

The occurred force produced by the stator current and permanent magnet in rotor disk is calculated as the following equation using Fleming's rule:

$$
d F_{x}=I\left(d r \times B_{g}\right)=A_{(r)}\left(d S \times B_{g}\right)
$$

where, if it expresses $I$ as the equivalent current of the stator, it is equal to the following equation:

$$
I d r=A_{(r)} d S, \sqrt{2} A_{(r)}=A_{m(r)}
$$

where, $d r$ and $d S$ are the differential radius and the differential surface in the rotor disk, respectively [1]. And $B_{g}$ is the vector of the axis-component of airgap flux density at a value of any differential radius $r$. And the peak value of armature line current density (specific electric loading) in the stator $A_{m(r)}$ is evaluated as:

$$
A_{m(r)}=\frac{\sqrt{2} m_{1} N_{1} I}{\pi r}
$$


where, $m_{1}$ is the number of phases, and $N_{1}$ is the number of winding coils per phase. Based on (4), the electromagnetic torque in the AFPMSMs is expressed as:

$$
d T_{d}=r d F_{x}=2 \alpha_{i} m_{1} N_{1} k_{w} I B_{g} r d r
$$

where, $a_{i}$ is the magnetic-field factor of the sinusoidal wave in air-gap $(=2 / \pi)$ and it assumes that the flux density in airgap $B_{g}$ is regular in the axis-direction.

Therefore, the resulting equation from (7) is given by:

$$
T_{d}=0.25 \alpha_{i} m_{1} N_{1} k_{w} I B_{g}\left(D_{o}^{2}-D_{i}^{2}\right)
$$

where, $D_{o}$ is the outer diameter, $D_{i}$ is the inner diameter.

\subsection{Back EMF (Electro-motive Force)}

The AFPMSM proposed in this paper has $p$ pieces of magnetic poles. The flux per pole is given by:

$$
\Phi_{\text {pole }}=\alpha_{i} \pi \frac{\left(D_{o}^{2}-D_{i}^{2}\right)}{4} \frac{B_{m g}}{2 p}
$$

where, $p$ is the number of magnetic poles, $B_{m g}$ is the maximum flux density in the airgap, $a_{i}$ is the factor of the sinusoidal wave in a magnetic-field $(=2 / \pi)$.

The RMS value of the induced $E M F$ in each phase $E_{f}$ is equal to:

$$
E_{f}=\sqrt{2} \pi n_{s} N_{1} k_{w} B_{m g} \frac{\left(D_{o}^{2}-D_{i}^{2}\right)}{8}
$$

where, $n_{s}$ is the revolution per second.

\subsection{Magnetic Equivalent Circuit Model}

The maximum flux density in each part of the magnetic circuit is obtained by using the principle of continuity of the flux flowing. The magnetic flux loop of the AFPMSM is indicated in Fig. 3. The corresponding lumped magnetic equivalent circuit is plotted in Fig. 4(a), where $R_{s}, R_{g}, R_{m}$ and $R_{m l}$ are the relative reluctances of stator iron, airgap, permanent magnet, and leakage path, respectively. $\Phi_{r}$, $\Phi_{m}, \Phi_{e}$ and $\Phi_{l}$ are the magnet flux, the efficient flux, and the leakage flux, respectively [4-5].

Reluctances of the permanent magnet and airgap can be expressed as:

$$
R_{m}=\frac{l_{m}}{\mu_{0} \mu_{r} A_{m}}
$$

$$
R_{g}=\frac{g_{e}}{\mu_{0} A_{g}}
$$

where, $l_{m}$ is the magnet length, $A_{m}$ is the cross-section area per pole, $A_{g}$ is the airgap area per pole, $\mu_{r}$ is the relative permeability of the permanent magnet, and $g_{e}$ is the effective airgap length. $g_{e}=k_{c} g$, where $k_{c}$ is the Carter coefficient given by the following equation:

$$
k_{c}=\left[1-\frac{1}{\frac{\tau_{s}}{w_{s}}\left(5 \frac{g_{c}}{w_{s}}+1\right)}\right]^{-1}
$$

where, $g_{c}$ is the effective airgap length for the Carter coefficient, $g_{c}=g+l_{m} / \mu_{r}$.

If the reluctance of the stator back irons can be neglected because the values are very small, the magnetic equivalent circuit can be further simplified as shown in Fig. 4(b). In this figure it is presented as the permeance instead of the reluctance in order to allow for simpler calculation [1]. The magnet leakage permeance is given as:

$$
P_{m l}=\frac{\mu_{0}\left(D_{o}-D_{i}\right)}{2 \pi} \ln \left(1+\pi \frac{g}{\tau_{f}}\right)
$$

where, $\tau_{f}$ is the magnet spacer width. Therefore, the magnet flux and the efficient flux can be defined as:

$$
\begin{gathered}
\Phi_{m}=\Phi_{r} \frac{P_{g}+4 P_{m l}}{2 P_{m}+P_{g}+4 P_{m l}} \\
\Phi_{e}=\Phi_{r} \frac{P_{g}}{2 P_{m}+P_{g}+4 P_{m l}}
\end{gathered}
$$

The flux densities in the airgap and stator back yoke are described as:

$$
\begin{gathered}
B_{g}=\frac{\Phi_{e}}{A_{g}}=\frac{B_{r} P_{g}}{2 P_{m}+P_{g}+4 P_{m l}} \frac{A_{m}}{A_{g}} \\
B_{s b}=\frac{\Phi_{e}}{2 A_{b y}}=\frac{B_{r} P_{g}}{2 P_{m}+P_{g}+4 P_{m l}} \frac{A_{m}}{2 A_{b y}}
\end{gathered}
$$

where, $A_{b v}$ is the area of the stator back yoke, and $B_{r}$ is the permanent flux density of the permanent magnet [6], [10]. 


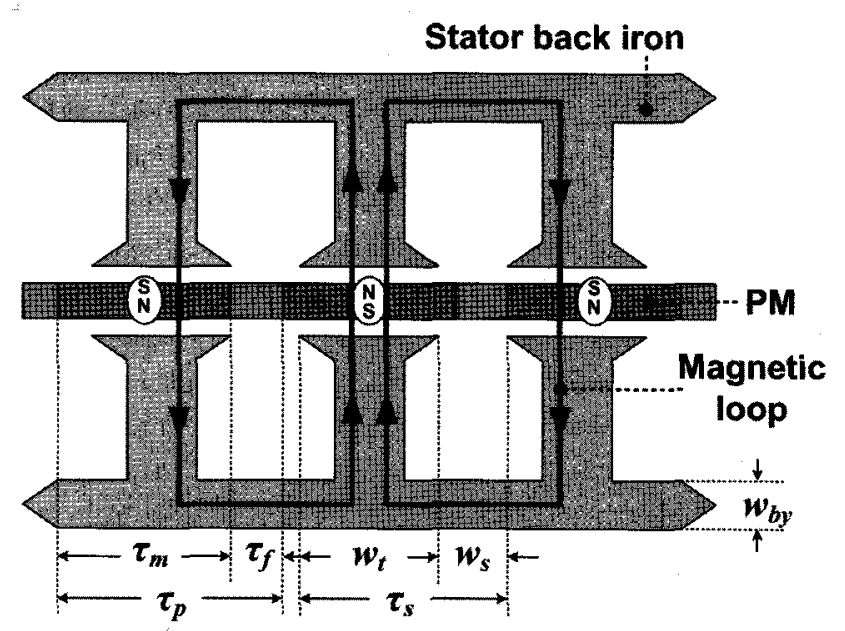

Fig. 3. The magnetic flux loop of the AFPMSM

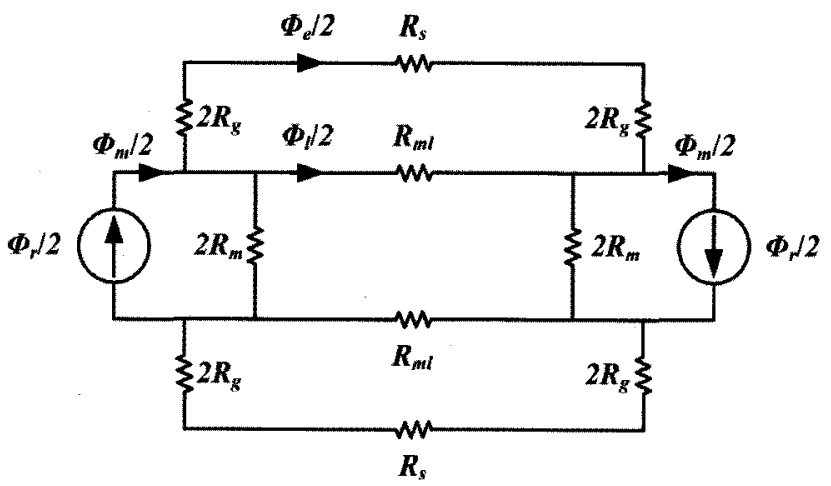

(a)

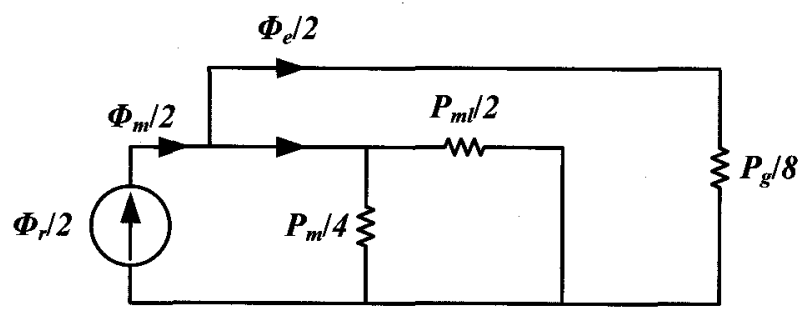

(b)

Fig. 4. (a) The lumped magnetic equivalent circuit, and (b) the simplified one.

The maximum flux density in the airgap has a relation to others: the tooth, back yoke, etc. The maximum flux densities in the airgap and the back yoke take the form of

$$
\begin{aligned}
& B_{g \max }=\frac{\left(D_{o}+D_{i}\right) \pi-2 w_{s} z}{\left(D_{o}+D_{i}\right) \pi} B_{d \max } \\
& B_{y \max }=\frac{\left(D_{o}+D_{i}\right) \pi-2 w_{s} z}{4 p \pi w_{b y}} B_{d \max }
\end{aligned}
$$

where, $B_{d \max }$ is the maximum flux density in the tooth of the stator, $w_{s}$ is the width of the stator slots, $z$ is the number of slots, and $w_{b y}$ is the width of the back yoke.

\subsection{Magnetic-motive force}

The inductance in the $\mathrm{d}$-axis direction is calculated as the ratio between the magnetic flux produced by the 3phase currents in the $d$-axis direction and the $d$-component of current flowing into the 1-phase winding coil:

$$
L_{d}=\frac{\Psi_{d}}{I_{d}}=\left(m_{1} N_{1} k_{w}\right) \frac{1}{I_{d}} \frac{\pi}{m_{1}}\left(D_{o}^{2}-D_{i}^{2}\right)\left(\frac{1}{2 \pi} B_{d}\right)
$$

If the permeability in the iron region is assumed to be infinite, the airgap flux density from the stator current in the d-axis direction can be evaluated as:

$$
B_{d}=\mu_{0} H=\mu_{0} \frac{M M F_{r e s}}{\left(2 l_{g}+\frac{l_{m}}{\mu_{m}}\right)}
$$

where, $M M F$ is calculated as $H=\frac{M M F}{l_{\text {total }}}$ using Ampere's law, $\oint H d l=N i=M M F, M M F_{\text {res }}$ produced by 3-phase stator windings is:

$$
M M F_{r e s}=1.35 N_{1} k_{w} I_{r m s}
$$

Therefore, the airgap flux density from the d-component of the current can be calculated as:

$$
B_{d}=\frac{1.35}{\sqrt{2}} \mu_{0} \frac{k_{w} N_{1} I_{d}}{\left(2 l_{g}+\frac{l_{m}}{\mu_{m}}\right)}
$$

As a result, the inductance in the d-axis direction is

$$
L_{d}=\frac{1.35}{2 \sqrt{2}}\left(m_{1} N_{1} k_{w}\right)^{2} \frac{\mu_{0}}{2 l_{g}+\frac{l_{m}}{\mu_{m}}}\left(D_{o}^{2}-D_{i}^{2}\right)
$$

where, because the permeability of the permanent magnet $\mu_{m}$ is generally $1.04 \sim 1.06$, it can be assumed as 1 .

And the inductance in q-axis direction is also calculated as similar to that in the d-axis.

$$
L_{q}=\frac{\Psi_{q}}{I_{q}}=\left(m_{1} N_{1} k_{w}\right) \frac{1}{I_{q}} \frac{\pi}{m_{1}}\left(D_{o}^{2}-D_{i}^{2}\right)\left(\frac{1}{2 \pi} B_{q}\right)
$$

If Ampere's law is applied, the airgap flux density and the inductance in q-axis direction are evaluated as: 


$$
\begin{gathered}
B_{q}=\mu_{0} H=\frac{M M F_{r e s}}{2 l_{g}}=\frac{1.35}{\sqrt{2}} \mu_{0} \frac{k_{w} N_{1} I_{q}}{2 l_{g}} \\
L_{q}=\frac{1.35}{2 \sqrt{2}}\left(m_{1} N_{1} k_{w}\right)^{2} \frac{\mu_{0}}{2 l_{g}}\left(D_{o}^{2}-D_{i}^{2}\right)
\end{gathered}
$$

\subsection{Stator Back Yoke Thickness}

Because the magnets produce standard flux density up to their surfaces, the total magnetic flux linkage in the airgap increases according to a higher radius and is calculated as:

$$
\Phi_{r}=B_{g} \theta_{m} r d r
$$

where, $\theta_{m}$ is the angle of pole pitch.

Only half of this magnetic flux linkage flows to the stator back yoke, so if maximum allowable flux density in the stator back yoke is $B_{\text {bymax }}$, the flux flowing into the back yoke is given by:

$$
\Phi_{b y}=B_{b y \max } w_{b y} k_{s t} d r
$$

where, $k_{s t}$ is the lamination stacking factor. As a result, by equating (23) and (24), the stator back yoke thickness is calculated as:

$$
w_{b y}=\frac{B_{g} \theta_{m} r}{2 B_{b y \max } k_{s t}}
$$

\subsection{Airgap Flux Linkage and Airgap flux density}

The airgap flux density, $\Phi_{g}$, is generally defined as:

$$
\Phi_{g}=\sqrt{\left(\Phi_{m}+L_{d} I_{d}\right)^{2}+\left(L_{q} I_{q}\right)^{2}}
$$

where, $\Phi_{m}$ is produced by permanent magnets, and $L_{d} I_{d}$ and $L_{q} I_{q}$ are produced by the inductance and the stator current in $d$ and $q$-axis respectively[9]. The resulting equation for the airgap flux linkage is given by the following equation:

$$
\Phi_{g}=k_{w} N_{1} B_{g} \frac{\left(D_{o}^{2}-D_{i}^{2}\right)}{2}
$$

where, the airgap flux density $B_{g}$ is defined as:

$$
B_{g}=\sqrt{\left(B+B_{d}\right)^{2}+\left(B_{q}\right)^{2}}
$$

\section{Optimum Size of the AFPMSM}

In axial flux machines, the diameter ratio, $D_{i} / D_{o}$, and airgap flux density are the two important design parameters having significant effect on the machine characteristics. Therefore, in order to find the optimum size of the machine performance, the diameter ratio and airgap flux density must be chosen carefully.

Table 2. Required Design Specification and Calculated Parameters of the AFPMSM.

\begin{tabular}{|c|c|c|}
\hline \multirow{4}{*}{ Rated } & Power, $\mathrm{kW}$ & 15 \\
& Voltage, V & 380 \\
& Current, A & $4 * 5.87$ \\
& Speed, rpm & 1800 \\
& Torque, Nm & 79.6 \\
\hline \multirow{2}{*}{ Stator } & Slot number & 18 \\
& Material & S45C \\
\hline \multirow{2}{*}{ Rotor } & Pole number & 16 \\
& Material & S45C \\
\hline \multirow{2}{*}{ Winding } & Turns/coil, turns & $90[$ turns $]$ \\
& Conductor Diameter & $1.2[\mathrm{~mm}]$ \\
\hline \multirow{3}{*}{ Magnet } & Br & $1.28[\mathrm{~T}]\left(20^{\circ}\right)$ \\
& Material & Nd-Fe-B \\
& Coercivity & $970[\mathrm{kA} / \mathrm{m}]$ \\
\hline \multicolumn{2}{|c|}{ Airgap length } & $2[\mathrm{~mm}]$ \\
\multicolumn{2}{|c|}{ Winding connection type } & $4-\mathrm{Y}$ \\
\hline \multicolumn{2}{|c|}{}
\end{tabular}

Table 2 displays the design specification of the AFPMSMs. Fig. 5 shows the power density variation as a function of air-gap flux density and the diameter ratio for the AFPMSMs. As can be seen from this figure, the maximum power density (or torque density) occurs at an airgap flux density of $1.0 \mathrm{~T}$ and a diameter ratio of $0.6 \mathrm{~m}$. For that maximum power density point the machine efficiency is $94.0 \%$. From this figure, the maximum power density is found to be $5.27 \mathrm{~W} / \mathrm{cm}^{3}[10]$.

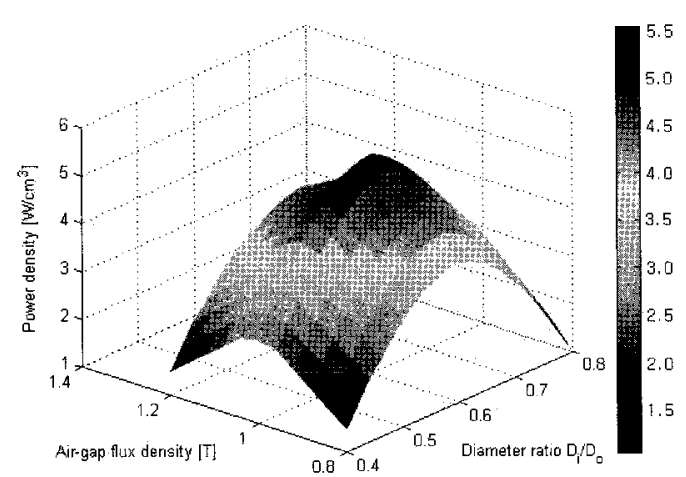

Fig. 5. Power density of AFPMSM vs. airgap flux density $\left(B_{g}\right)$ vs. diameter ratio $\left(D_{i} / D_{o}\right)$ 


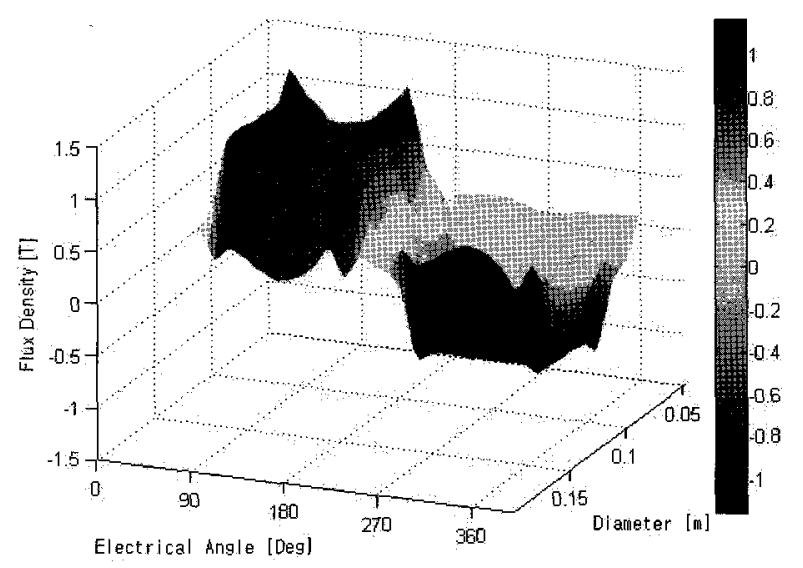

Fig. 6. The airgap magnetic flux density for AFPMSMs

Fig. 6 presents airgap flux density variation as a function of the diameter and various electrical angles for the AFPMSMs. From this figure, the average flux density, which is found to be about $1.0 \mathrm{~T}$, occurs from the inner diameter to the outer diameter.

\section{Conclusion}

The focus of this article has been to obtain the characteristic equations for the design and to find the optimum sizing for the output power. The electromagnetic design has been performed by applying the characteristic equations to the new type AFPMSM. In order to optimize the machine, the power density, the diameter ratio and the airgap flux density have been chosen carefully. The machines were compared in terms of the power density and the results were applied for design of this machine.

\section{Acknowledgements}

This work was supported by KEMCO.

\section{References}

[1] M. Cirani, P. Thelin and C. Sadarangani, "Design procedure for an AFPM machine for field-weakening applications", Proceedings of the Nordic Workshop on Power and Industrial Electronics, NORpie 2002, Stockholm, Sweden, August.

[2] F. Caricchi, F. Crescimbini, E. Fedeli and G. Noia, "Design and Construction of a Wheel-Coupled Axial-Flux PM Motor Prototype for EVs", Conf. Record of the 1994 Ind. Appl. Conference, Denver, Colorado, USA, col. 1, pp. 254-261, Oct. 1994.
[3] P. Campbell, "The Magnetic Circuit of an Axial Field DC Electrical Machine", IEEE Trans. on Magnetics, pp. 1541-1543, Sept. 1975.

[4] C.C. Chan, "Axial-Field Electrical Mahines-Design and Application", IEEE Trans. on Energy Conversion, pp. 294-300, June 1987.

[5] R. Wallace, L. Moran, G. Cea, F. Peraz, "Design and Construction of Medium Power Axial Flux Induction Motors", IEE Electrical Machines and Drives, pp. 260-265, Sep 1991.

[6] M. Aydin, S. Husang, and T. A. Lipo, "Optimum design and 3D finite element analysis of non-slotted and slotted internal rotor type axial flux PM disc machines", Power Engineering Society Summer Meeting, pp. 1409-1416, 2001.

[7] F. Caricchi, F. Crescimbini, O. Honorati, and E. Santini, "Performance evaluation of an axial flux PM generator", Proceedings of International Conference on Electrical Machines (ICEM), pp. 761-765, 1992.

[8] R. J. Hill-Cottingham, P. C. Coles, J. F. Eastham, F. Profumo, A. Tenconi, G. Gianolio, "Multi-disc axial flux stratospheric propeller drive", Proc. of IEEE IAS Annual Meeting Conference Record 2001, vol. 3, pp. 1634-1639, 2001.

[9] F. Caricchi, F. Crescimbini, O. Honorati, Modular, "Axial-flux permanent magnet motor for ship propulsion drives", IEEE Trans. on Energy Conversion, vol. 14, pp. 673-679, 1999.

[10] Z. Q. Zhu and D. Howe, "Influence of design parameters on cogging torque in permanent magnet motors", IEEE Transactions on Energy Conversion, Vol. 15, No. 4, pp. 2000.

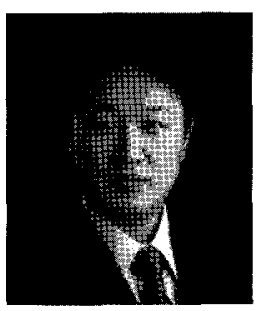

Won-Young Jo

$\mathrm{He}$ was born in Busan, Korea. He received his B.S. degree in Electrical Engineering from Dong-A University, Busan, Korea, in 2004. He is currently working towards his M.S. degree in Electrical Engineering, also at Dong-A University. His research interests are motor and drive design, and power electronics.

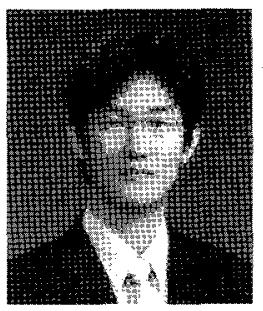

In-Jae Lee

$\mathrm{He}$ was born in Busan, Korea. He received his B.S. degree in Electrical Engineering from Dong-A University, Busan, Korea, in 2004. He is currently working towards his M.S. degree in Electrical Engineering, also at Dong-A University. His research interests are motor and drive design, and power electronics. 


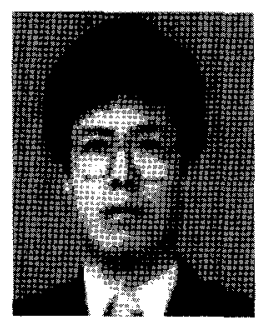

\section{Yun-Hyun Cho}

He received his B.S., M.S. and Ph.D. degrees in Electrical Engineering from Hanyang University in 1984, 1986 and 1991, respectively. From 1990 to 1995 , he was a Senior Researcher at the Mechatronics Research Group of the Korea Electrotechnology Research Institute. $\mathrm{He}$ is currently an Assistant Professor of Electrical Engineering at Dong-A University, Busan, Korea.

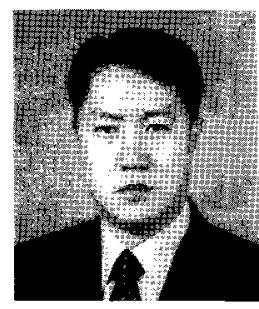

\section{Dae-Hyun Koo}

He received his B.S. and M.S. degrees in Electrical Engineering from Hanyang University in 1989 and 1991, respectively. From 1991, he has worked at the Korea Electrotechnology Research Institute (KERI). In 2002, he received a $\mathrm{Ph}$. D. degree from Dong-A University. He is currently a Director of the Mechatronics Research Group, KERI.

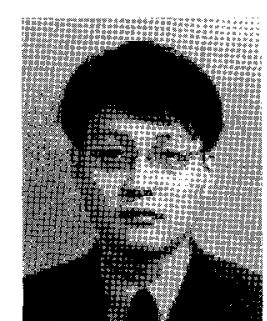

\section{Yon-Do Chun}

He received his B.S., M.S. and Ph.D. degrees in Electrical Engineering from Hanyang University in 1996, 1998 and 2001 , respectively. He is currently a Senior Researcher at the Mechatronics Research Group, Korea Electrotechnology Research Institute. 